\title{
Morphological and chemical characterization of highly ordered conical-pore anodic alumina prepared by multistep citric acid anodizing and chemical etching process
}

\author{
Małgorzata Norek $^{1}$ - Maksymilian Włodarski ${ }^{2}$
}

Published online: 11 April 2017

(C) The Author(s) 2017. This article is an open access publication

\begin{abstract}
Highly ordered, conical-pore anodic alumina (AAO) membranes with interpore distance $\left(D_{c}\right)$ between ca. 530 and $620 \mathrm{~nm}$ and thickness ranging between 2.4 and $7.8 \mu \mathrm{m}$, were produced. In the fabrication process aluminum surface was first pre-patterned by the anodization in etidronic acid solution. Then, the regular arrays of $\mathrm{Al}$ concaves were used as nucleation sites to grow AAO during the second anodization, which was carried out in highly concentrated citric acid solution $(20 \mathrm{wt} \%)$ and at relatively high temperature $\left(33-35^{\circ} \mathrm{C}\right)$. The conical pore shape was engineered by a multistep process combining anodization in the citric acid electrolyte and the subsequent chemical pore broadening in phosphoric acid solution. The morphological analyses has revealed that the geometrical parameters of the $\mathrm{Al}$ concaves were successfully transferred to the AAO membranes. Furthermore, FTIR spectra analysis confirmed that the electrolyte species, such as phosphonate and citric ions, are being embedded into the AAO framework during the anodization. The graded-index structure formed in AAO can be used for a production of antireflective coatings operating in a broad spectral range.
\end{abstract}

Keywords Etidronic acid · Citric acid · Guided anodization $\cdot$ Tapered pores $\cdot$ IR spectra

Małgorzata Norek

malgorzata.norek@wat.edu.pl; mnorek73@gmail.com

1 Department of Advanced Materials and Technologies, Faculty of Advanced Technologies and Chemistry, Military University of Technology, Str. Kaliskiego 2, 00-908 Warszawa, Poland

2 Institute of Optoelectronics, Military University of Technology, Str. Kaliskiego 2, 00-908 Warszawa, Poland

\section{Introduction}

Anodic alumina (AAO) membrane is a porous material with uniform, parallel nanochannels that can be used to produce various nanostructures $[1,2]$. Its geometrical parameters, such as interpore distance or the membrane thickness, can be fully regulated by anodizing conditions [3]. While the interpore distance $\left(D_{c}\right)$ in the AAO is controlled mainly by the applied voltage, the AAO thickness depends also on current density and the anodization time. It is well known that highly ordered AAO with pores arranged into a close-packed hexagonal structure are obtained solely within a relatively narrow window of operating conditions (proper voltages, concentrations of electrolyte, temperature, etc.), so-called self-ordering conditions (or self-ordering regimes). Out of these regimes, the pore arrangement deteriorates. The self-ordering conditions were found in many electrolytes including oxalic, sulfuric, phosphoric, or etidronic acid solution [4]. The dissociation constants (pKa) of a given acid determines the critical potential (the highest self-ordering voltage) under which it is still possible to conduct a stable anodization. The highest critical potential of $270 \mathrm{~V}$ was applied during the anodization in etidronic acid solution $[5,6]$. The AAO with $D_{c} \sim 700 \mathrm{~nm}$ was thus obtained. Anodization under voltages $>300 \mathrm{~V}$ were performed in citric acid electrolytes and resulted in the AAO with ultra-large $D_{c}$ (in micrometer scale) [7-9]. However, application of the high voltages and relatively low concentration of citric acid solutions caused formation of a non-uniform anodic oxide without hexagonal, closepacked arrangement of pores [10-12].

Guided anodization is one of the most efficient method to produce highly ordered AAO even out of the selfordering regimes. A perfectly ordered AAO membranes were synthesized by application of expensive and time 
consuming pre-patterning methods [13-15]. However, a very regular AAO membranes can be also produced by a much more affordable experimental approach, which is based on application of hard anodization (HA) in the first step, followed by the mild anodization (MA) in the second step [16-18]. In this approach, a highly regular nano-concave arrays, patterned on aluminum upon removal of AAO formed in HA, serve as nucleation sites for AAO growth during MA.

It is also possible to design a various shape of pores in AAO by application of a pulse anodization methods $[19,20]$. Recently, AAOs with tapered pores and pitch size in the range of 100-490 $\mathrm{nm}$ were fabricated [21-27]. The tapered-pore AAO is very attractive porous material because it can act as a layer for the gradually changing refractive index. The graded-index nanostructures are insensitive to polarization effects, guaranteeing broad-band and omni-directional anti-reflectivity properties required for a perfect anti-reflective (AR) performance [28-30]. The AAO templates with $D_{c}$ between 100 and $200 \mathrm{~nm}$ were successfully used for preparing polymer AR coatings operating in visible and NIR range [31, 32]. It is, however, expected that upon the increase of AAO geometrical parameters, including $D_{c}$ and AAO thickness, the AR properties can be expanded beyond the NIR spectral range [33,34].

In this work, highly ordered tapered-pore AAO membranes, with $D_{c}$ in the range $530-620 \mathrm{~nm}$ and thickness ranging between 2.4 and $7.8 \mu \mathrm{m}$, are fabricated. The tapered-pore AAO matrices of such geometry and a high level of pore ordering have not been produced before. In the fabrication process, a guided anodization was used. First, aluminum surface was pre-patterned (Al concave arrays at the surface) during the self-ordering anodization conducted in $0.3 \mathrm{M}$ etidronic acid solution. Next, the regular $\mathrm{Al}$ concave arrays were used to grow AAO by high-temperature, high-concentration citric acid anodizing. The pores with conical shape were engineered by alternating anodization in the citric acid electrolyte and etching in phosphoric acid solution. The guided anodization resulted in a production of highly ordered, close-packed hexagonal arrays of pores in AAO, which was not observed before during the anodization in citric acid electrolyte. Moreover, a detailed morphological and chemical analysis of the obtained porous material was performed and discussed. It was confirmed that electrolyte species, such as phosphonate or citric acid ions, are being incorporated into the AAO framework during the synthesis.

\section{Experimental}

High-purity aluminum foil $(99.9995 \%$ Al, Goodfellow, UK) with a thickness of about $0.25 \mathrm{~mm}$ was cut into rectangular specimens $(2 \mathrm{~cm} \times 1 \mathrm{~cm})$. Before the anodization process the $\mathrm{Al}$ foils were degreased in acetone and ethanol and subsequently electropolished in a 1:4 mixture of $60 \% \mathrm{HClO}_{4}$ and ethanol at $0{ }^{\circ} \mathrm{C}$, constant voltage of $20 \mathrm{~V}$, for $2.5 \mathrm{~min}$. Next, the samples were rinsed with a distilled water, ethanol and dried. As prepared Al specimens were insulated at the back and the edges with acid resistant tape, and serve as the anode. A Pt grid was used as a cathode and the distance between both electrodes was kept constant (ca. $5 \mathrm{~cm}$ ). A large, $1 \mathrm{~L}$ electrochemical cell and cooling bath thermostat (model MPC-K6, Huber company) were employed in the anodizing process. An adjustable DC power supply with voltage range of $0-300 \mathrm{~V}$ and current range of $0-5 \mathrm{~A}$, purchased from NDN, model GEN750_1500 TDK Lambda, was used to control the applied voltage.

The first anodization was carried out in $0.3 \mathrm{M}$ etidronic acid solution (Sigma-Aldrich) at 210, 235, and $260 \mathrm{~V}$ and temperature of 38,27 , and $21^{\circ} \mathrm{C}$, respectively (the formed oxides are denoted as: eAAO-1, eAAO-2, and eAAO3 , respectively). Before application of the high voltages, the samples were first pre-anodized at $80 \mathrm{~V}$ (for $\sim 1 \mathrm{~min}$ ). Then, the voltage was increased to the target values and all samples were anodized for $8 \mathrm{~h}$. As obtained alumina was chemically removed in a mixture of $6 \mathrm{wt} \%$ phosphoric acid and $1.8 \mathrm{wt} \%$ chromic acid at $60^{\circ} \mathrm{C}$ for $180 \mathrm{~min}$. The respective $\mathrm{Al}$ concave arrays obtained after the eAAOs removal are denoted as $\mathrm{Al}$ conc- $1, \mathrm{Al}$ conc-2, and $\mathrm{Al}$ conc-3. Second anodization was performed in the $20 \mathrm{wt} \%$ citric acid solution (the respective samples are denoted as cAAO-1, c-AAO-2, and cAAO-3) under different anodizing voltage and temperature values: the sample cAAO-1 was anodized at $210 \mathrm{~V}$ and $35^{\circ} \mathrm{C}$, the sample cAAO-2 at $230 \mathrm{~V}$ and $35^{\circ} \mathrm{C}$, and the sample cAAO-3 at $250 \mathrm{~V}$ and $33^{\circ} \mathrm{C}$ (Table 1). For pore broadening a $10 \mathrm{wt} \%$ solution of phosphoric acid was used. The pore shaping was made by alternating citric acid anodizing and pore etching in phosphoric acid. In the Fig. 1, the scheme of the pore engineering process is presented, where the etching steps were denoted by Roman numerals (I, II, ..,i), whereas the anodization steps were marked by Arabic numerals $(1,2, \ldots, \mathrm{i})$.

Morphology of PAAs was studied using field-emission scanning electron microscope FE-SEM (FEI, Quanta) equipped with energy dispersive X-ray spectrometer (EDS).

To obtain geometrical parameters of the fabricated $\mathrm{Al}$ concaves and cAAO membranes, Fast Fourier transforms (FFTs) were generated based on three SEM images taken at the same magnification for every anodizing voltage, and were further used in calculations with WSxM software [35, 36]. The average interpore distance $\left(D_{c}\right)$ was estimated as an inverse of the FFT's radial average from three FE-SEM images for each sample [37]. To estimate a semi-quantitative regularity parameter $(R)$, radial average was generated 
Table 1 Interpore distance $\left(D_{c}\right)$ and regularity parameter $(R)$ determined for the Al concave arrays (Fig. 2) and the conical-pore AAO membranes (cAAOs) (Fig. 3)

\begin{tabular}{llll}
\hline $\begin{array}{l}\text { Sample name } \\
\text { 1st anodization parameters }\end{array}$ & $\begin{array}{l}\mathrm{Al} \mathrm{conc}-1 \\
210 \mathrm{~V} \mathrm{~T}=38^{\circ} \mathrm{C}\end{array}$ & $\begin{array}{l}\mathrm{Al} \mathrm{conc}-2 \\
235 \mathrm{~V} \mathrm{~T}=27^{\circ} \mathrm{C}\end{array}$ & $\begin{array}{l}\mathrm{Al} \mathrm{conc}-3 \\
260 \mathrm{~V} \\
\mathrm{~T}=21^{\circ} \mathrm{C}\end{array}$ \\
\hline $\begin{array}{l}\mathrm{Al} \text { concaves } \\
D_{c} \text { (nm) }\end{array}$ & $539 \pm 13$ & $581 \pm 10$ & $647 \pm 17$ \\
$R$ (a.u.) & $5.1 \pm 0.3$ & $4.5 \pm 0.7$ & $2.8 \pm 1.1$ \\
\hline Sample name & $\mathrm{cAAO}-1$ & $\mathrm{cAAO}-2$ & $\mathrm{cAAO}-3$ \\
2nd anodization parameters & $210 \mathrm{~V}$ & $230 \mathrm{~V}$ & $250 \mathrm{~V}$ \\
& $\mathrm{~T}=35^{\circ} \mathrm{C}$ & $\mathrm{T}=35^{\circ} \mathrm{C}$ & $\mathrm{T}=33^{\circ} \mathrm{C}$ \\
\hline Conical-pore cAAO & & & $569 \pm 9$ \\
$D_{c}$ (nm) & $532 \pm 11$ & $4.9 \pm 0.6$ & $623 \pm 12$ \\
$R$ (a.u.) & $5.5 \pm 0.2$ & $4.4 \pm 0.8$ \\
\hline
\end{tabular}

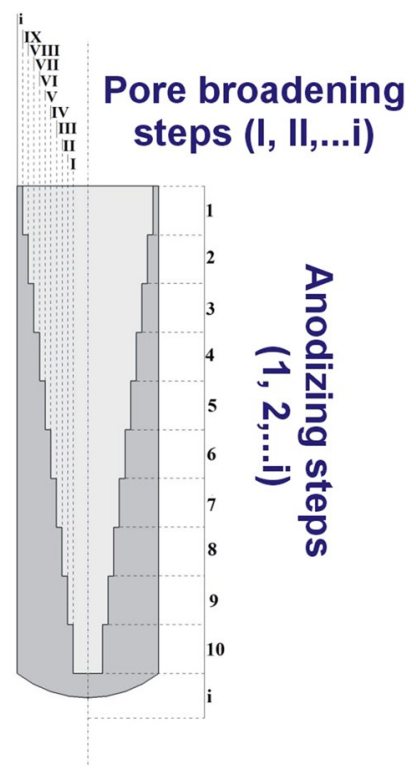

Fig. 1 A scheme demonstrating a tapered pore structure engineered by a multistep anodization in citric acid electrolyte and pore broadening in phosphoric acid solution

from each FFT image. The $R$ was calculated according to the following formula (1) [38]:

$R=\frac{H}{W_{1 / 2}} \cdot \frac{\sqrt{n}}{S^{3 / 2}}$

where $n$ is the number of pores, $S$ is the analyzed surface area, $H$ is the maximal intensity value of the FFT intensity profile, and $W_{1 / 2}$ is the width of the intensity profile at half of its height.

FTIR spectra were recorded using Spectrum GX Optica spectrometer from Perkin-Elmer with diffuse reflectance accessory. Light scattered from surface of the sample was collected in a full $\pi$ steradian angle. The angle of incidence was $38^{\circ}$. Aluminum sheet was used as a $100 \%$ reflectance reference sample.

\section{Results and discussion}

Etidronic acid anodizing was conducted according to the approach presented elsewhere $[5,6]$. In this approach, the anodization starts at relatively low voltage $(80 \mathrm{~V})$ which is subsequently increased to a target value. As an effect, the top part of the AAO is highly irregular. Therefore, the eAAO membranes produced during the first anodization in $0.3 \mathrm{M}$ etidronic acid solution at various anodizing conditions were removed in order to obtain a regular array of concaves on $\mathrm{Al}$ surface, which were subjected to morphological analysis and further fabrication process. In Fig. 2, SEM images (Fig. 2a, d, g), 2D (Fig. 2b, e, h) and 3D FFT images (the insets in the corresponding SEM images), and radial averages (Fig. 2c, f, i) of Al concaves, are demonstrated. The images in Fig. 1 show that highly ordered pore assembly was fabricated. The pores are uniform and organized into a hexagonal close-packed structure. However, in the $\mathrm{Al}$ conc- 3 the domains of an ideal hexagonal pore arrangement are smaller as compared to the domains in the Al conc- 1 and Al conc- 2 samples. This is also reflected in more blurred FFT rings and, consequently, broader peaks in the radial average profile (Fig. 2h, i). The lower pore regularity is most likely due to the anodization conditions that were slightly out of the self-ordering regime [39, 40]. The anodization at $260 \mathrm{~V}$ was carried out at temperature of $21^{\circ} \mathrm{C}$ which was probably too low to provide sufficient forces (e.g. mechanical stress at the pore bottom) to form larger domains of hexagonal pore ordering. However, it was difficult to maintain a stable anodization at temperature higher than $21^{\circ} \mathrm{C}$ within a sufficiently long time to allow 

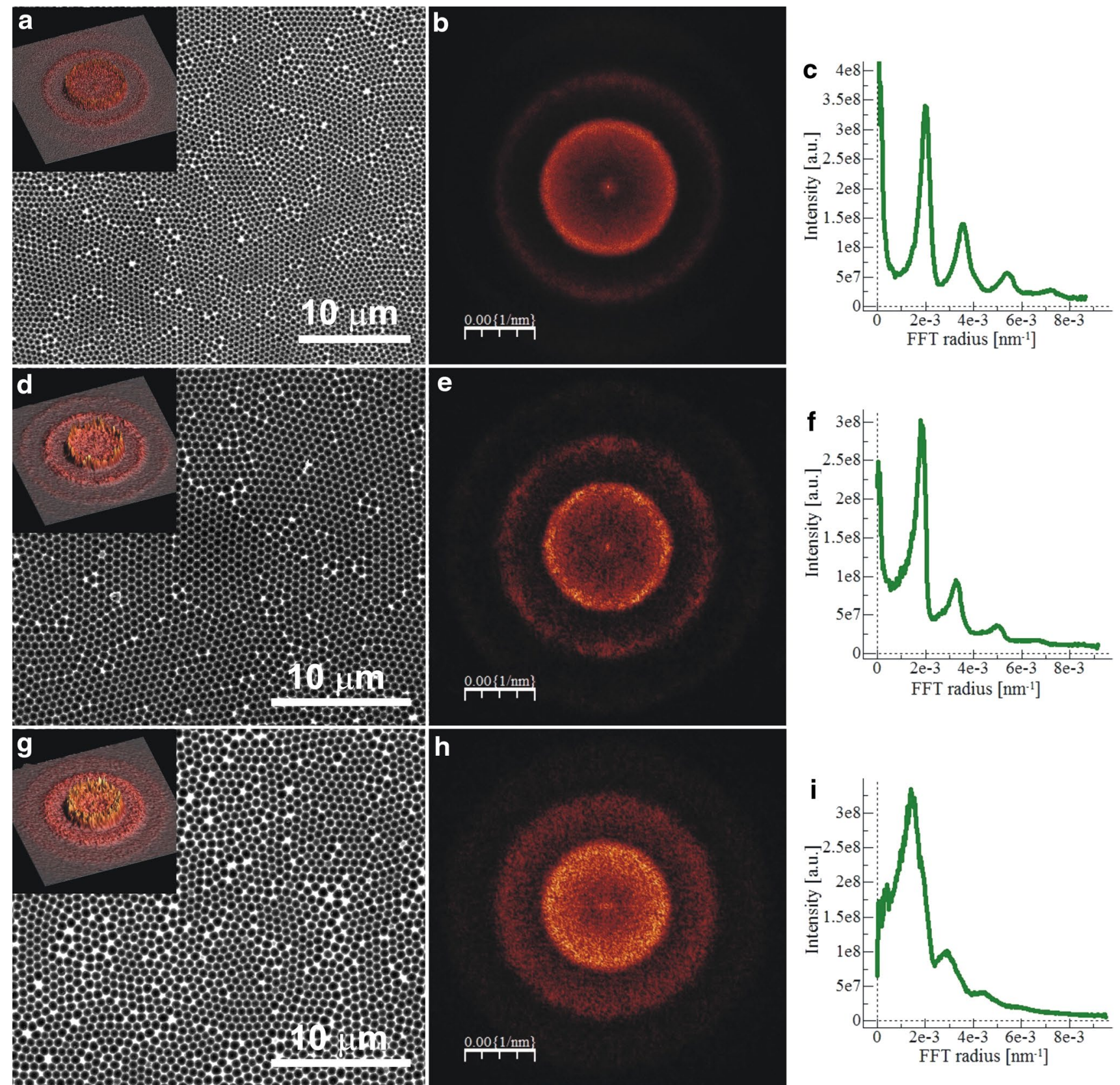

Fig. 2 SEM images $(\mathbf{a}, \mathbf{d}, \mathbf{g})$, fast Fourier transforms (FFT) $(\mathbf{b}, \mathbf{e}, \mathbf{h})$ with their radial averages $(\mathbf{c}, \mathbf{f}, \mathbf{i})$ of $\mathrm{Al}$ conc-1 (a, b, $\mathbf{c}), \mathrm{Al}$ conc-2 (d, e, f), and $\mathrm{Al}$ conc-3 (g, h, i) samples; the insets in the SEM images show the 3D FFT images of the respective samples

for an optimal pore reorganization process. The shorter anodization time at temperature of $23^{\circ} \mathrm{C}$ provided even poorer pore arrangement. On the other hand, the anodization at temperature higher than $23^{\circ} \mathrm{C}$ resulted most often in the sample burning. Therefore, it was assumed that the anodization parameters were optimal for this sample. In Table 1 the interpore distance $\left(D_{c}\right)$ values determined for the $\mathrm{Al}$ concave arrays are given. With the increasing anodizing potential the $D_{c}$ increases from around $539 \mathrm{~nm}$ for the sample anodized at $210 \mathrm{~V}$ to around $647 \mathrm{~nm}$ for the sample anodizes at $260 \mathrm{~V}$. Moreover, a semi quantitative $R$ parameter was calculated based on the Eq. 1 (Experimental part) to estimate the level of the hexagonal pore arrangement. As can be seen, the $R$ values are significantly higher for the $\mathrm{Al}$ conc- 1 and $\mathrm{Al}$ conc- 2 samples as compared to the sample $\mathrm{Al}$ conc-3.

In order to obtain the tapered pore structure in AAO, the Al concaves were subjected to a multistep process of anodization in citric acid electrolyte and subsequent pore etching in $10 \mathrm{wt} \%$ phosphoric acid solution at room temperature, 

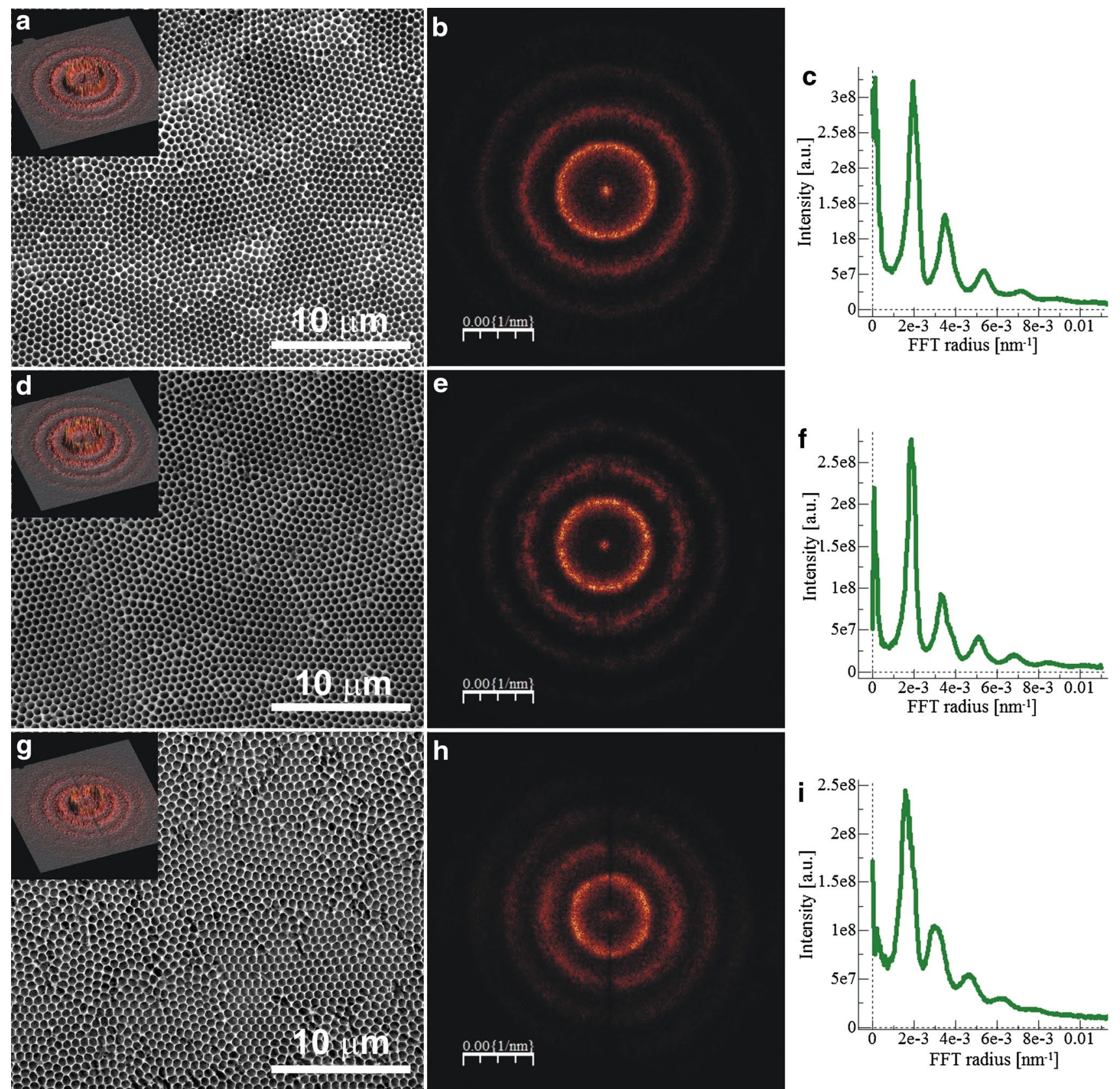

Fig. 3 SEM images (a, d, $\mathbf{g})$, fast Fourier transforms (FFT) (b, e, h) with their radial averages $(\mathbf{c}, \mathbf{f}, \mathbf{i})$ of the top surface of cAAO-1 (a, b, $\mathbf{c}$ ), cAAO-2 (d, e, f), and cAAO-3 (g, h, i) membranes; the insets in the SEM images show the 3D FFT images of the respective samples

using similar approach to that presented in the previous works [21-24]. The process was repeated until the desired pore shape and AAO membrane thickness was obtained. The citric acid was chosen because it allows for a stable anodization at high voltage values [41]. In the guided anodization it is important to adjust the operating conditions to the distance between nano-concave centers on the $\mathrm{Al}$ surface. It is generally accepted that the applied voltage should be close to the $D_{c} / \zeta$ ratio, where the factor $\zeta \sim 2.5$ for mild anodization [42]. Consequently, the voltage of 210 ,
230 , and $250 \mathrm{~V}$ were selected for the anodization of the Alconc-1, Al-conc-2, and Al-conc-3 samples, respectively. The parameters used for the synthesis of tapered-pore cAAO membranes are gathered in Table 2. The anodization and chemical etching times were set based on previously estimated AAO growth rate (around 2.5, 3.7, and $6.6 \mu \mathrm{m} / \mathrm{h}$, for cAAO-1, cAAO-2, and cAAO-3, respectively) and the rate of pore diameter broadening $(41-45 \mathrm{~nm} / \mathrm{h})$, respectively. The number of etching steps was adjusted to the $D_{c}$ values. In general, the greater the $D_{c}$ values, the larger 
Table 2 The parameters used to fabricate conical-pore AAO membranes (cAAO)

\begin{tabular}{lllllll}
\hline Sample & $\begin{array}{l}\text { Tempera- } \\
\text { ture }\left({ }^{\circ} \mathrm{C}\right)\end{array}$ & Voltage (V) & $\begin{array}{l}\text { Anodizing } \\
\text { steps }\end{array}$ & $\begin{array}{l}\text { Anodizing time } \\
\text { by step }(\mathrm{min})\end{array}$ & $\begin{array}{l}\text { Pore broad- } \\
\text { ening steps }\end{array}$ & $\begin{array}{l}\text { Pore broadening } \\
\text { time by step (h) }\end{array}$ \\
\hline cAAO-1 & 35 & 210 & 10 & 5 & 9 & 1 \\
cAAO-2 & 35 & 230 & 11 & 5 & 10 & 1 \\
cAAO-3 & 33 & 250 & 12 & 5 & 11 & 1 \\
\hline
\end{tabular}

${ }^{a}$ Except the duration of the first anodization step which was always $15 \mathrm{~min}$ should be the number of the etching steps. Moreover, in the pore shape engineering a slight increase of pore diameter with anodizing voltage was taken into account [43]. The effect was previously ascribed to the high current density and strong chemical dissolution enhanced by the electric field [44].

In Fig. 3, SEM images (Fig. 3a, d, g), 2D (Fig. 3b, e, h) and 3D FFT images (the insets in the corresponding SEM images), and radial averages (Fig. 3c, f, i) of the top surface of the cAAO membranes, are demonstrated. The hexagonal pore arrangement is excellent for all samples, which is also reflected in the distinct FFT rings and narrow peaks in the radial average profiles. The high level of pore ordering was not observed before in the AAO obtained by a standard anodization in citric acid $[8,10-12]$, and can be attributed to a guided role of $\mathrm{Al}$ surface pre-patterned during the first anodization in etidronic acid electrolyte. In the guided anodization periodic arrangement of concavities on aluminum surface serves as nucleation sites for undisturbed growth of anodic alumina. The growth position of the pores is limited by the pre-patterned design and is restricted to the inner corner/electrolyte interface, where a maximum dissolution rate of $\mathrm{Al}^{3+}$ is localized [45]. Therefore, the geometrical features of $\mathrm{Al}$ concaves, such as hexagonal pore regularity and the pitch size, are directly transferred the corresponding AAO membranes. The interpore distance $\left(D_{c}\right)$ and regularity parameter $(R)$ determined for the cAAO membranes are given in Table 1. Within the margin of error, both parameters are comparable for the eAAO- 1 and eAAO-2 membranes and the corresponding $\mathrm{Al}$ concaves. However, the $R$ parameter for the sample cAAO-3 is evidently greater than the $R$ determined for the $\mathrm{Al}$ conc- 3 , suggesting the improvement of the hexagonal pore arrangement after the multistep anodization in citric acid electrolyte. Moreover, because the pores are now densely arranged into hexagonal close-packed structure over relatively larger domains, the $D_{c}$ value has decreased as compared to the $D_{c}$ determined for the $\mathrm{Al}$ conc- 3 . The observation implies that the guided role of the nucleation sites on the $\mathrm{Al}$ surface was reinforced in this sample by the anodization conditions applied in the second anodization. The anodization was carried out in relatively high concentrated citric acid solution (20 wt\%) and at relatively high temperature values $\left(33-35^{\circ} \mathrm{C}\right)$, which apparently provided additional forces in the pore reorganization process.

The cross sectional view of the cAAO membranes are shown in Fig. 4a-c. It is clearly seen that cAAO films with conical pore shape were successfully manufactured. The thickness of the cAAO films (the height of the cone) was around $2.4,3.9$, and $7.8 \mathrm{~nm}$ in the sample cAAO-1, cAAO2 , and cAAO-3, respectively.

In Fig. 5, FTIR spectra of the cAAO membranes are shown along with the spectra of the eAAO- 1 and the respective Al conc-1 samples. The FTIR spectrum of
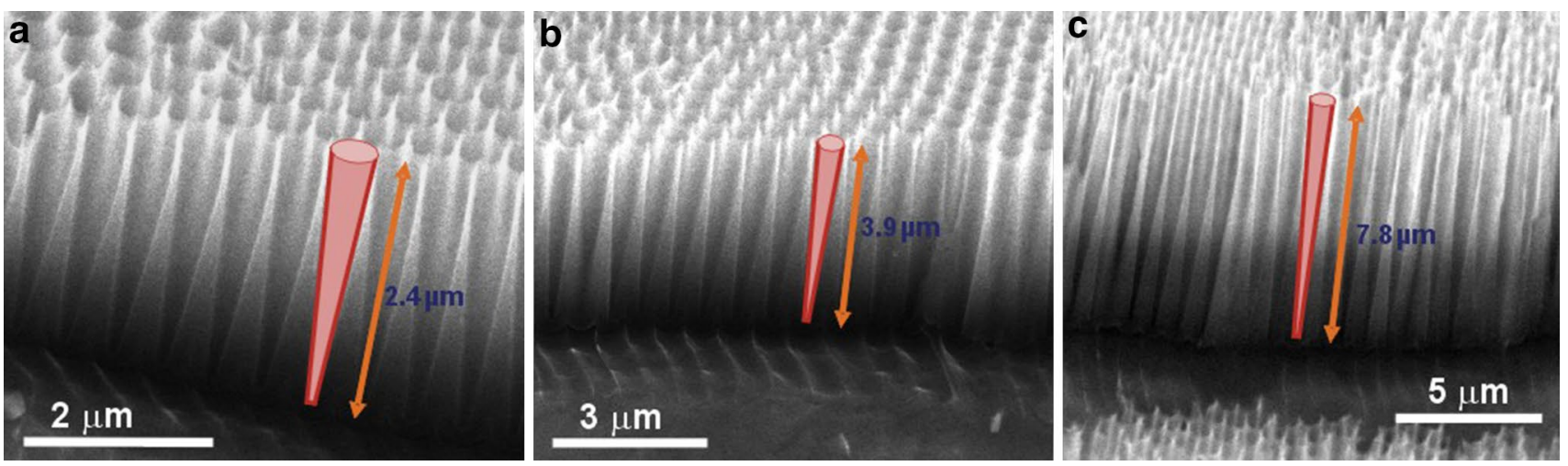

Fig. 4 SEM images of cross sectional views of the tapered-pore cAAO-1 (a), cAAO-2 (b), and cAAO-3 (c) membranes 

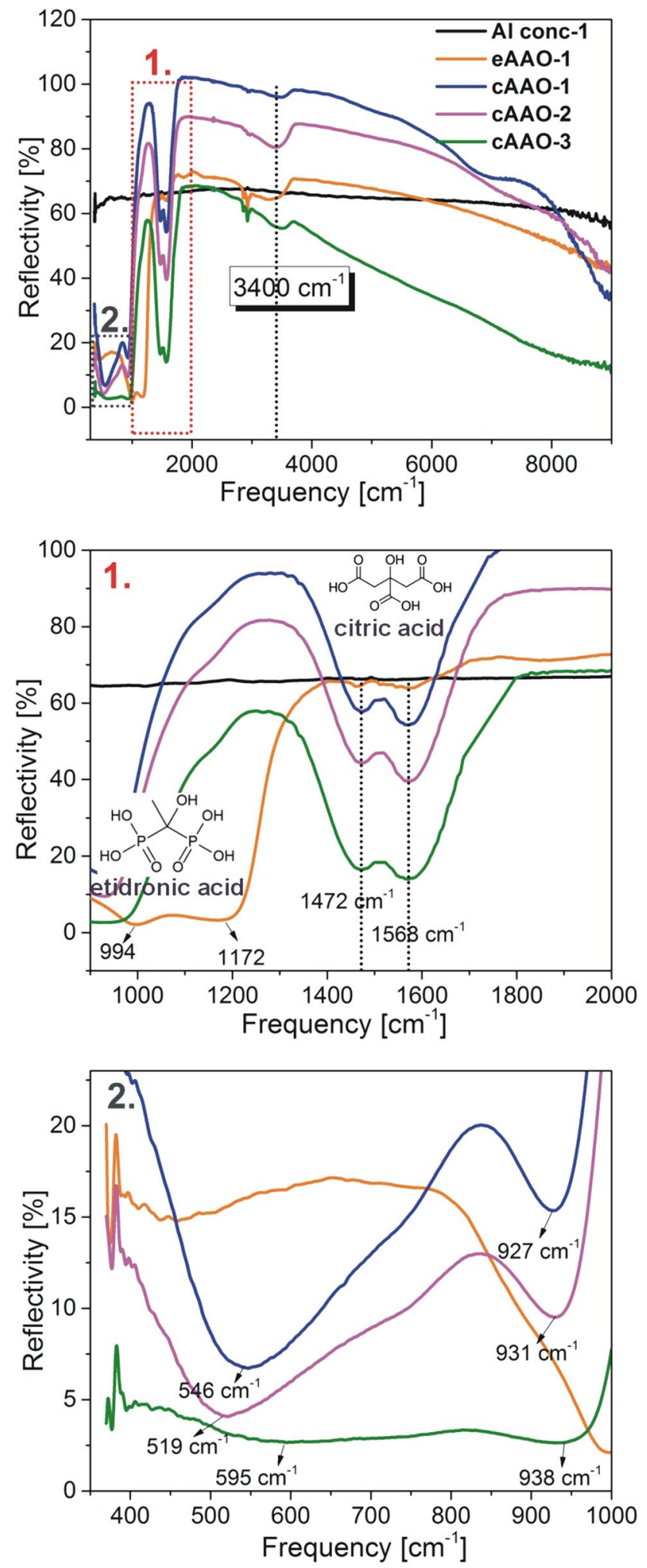

Fig. 5 IR spectra of the Al conc-1, eAAO-1, and the tapered-pore cAAO-1, cAAO-2, and cAAO-3 membranes
Al conc-1 sample is flat in the whole measured region, in contrast to the spectra of AAOs, where characteristic bands are clearly distinguishable. The broad dip centered at around $3400 \mathrm{~cm}^{-1}$ visible in all AAO membrane spectra is typical for valence vibrations of adsorbed water and $\mathrm{OH}^{-}$groups [46, 47]. In the FTIR spectrum of the sample eAAO-1 prepared in etidronic acid (HEDP) two dips at 994 and $1172 \mathrm{~cm}^{-1}$ can be distinguished. Both dips are characteristic for phosphonates, which display bands due to the $\mathrm{P}-\mathrm{O}$ stretching vibration in the $900-1200 \mathrm{~cm}^{-1}$ range [48, 49]. The dip at $994 \mathrm{~cm}^{-1}$ can be assigned the symmetric vibration of $\mathrm{P}-\mathrm{O}$ chemical bond $\left(\nu_{\mathrm{S}} \mathrm{P}-\mathrm{O}\right)$ of $\mathrm{PO}_{3}{ }^{2-}$ group, whereas the one at $1172 \mathrm{~cm}^{-1}$ corresponds most probably to the $\mathrm{P}=\mathrm{O}$ vibrations. The IR spectra of the $\mathrm{cAAO}$ membranes synthesized during the multistep anodization in citric acid are completely different. Two distinct dips at 1472 and $1568 \mathrm{~cm}^{-1}$ appeared, which can be interpreted in terms of the internal frequencies of the citrate ion [47, 50, 51]. The bands can be ascribed to the symmetric $\left(1472 \mathrm{~cm}^{-1}\right)$ and antisymmetric $\left(1568 \mathrm{~cm}^{-1}\right)$ oscillations of the carboxylic ion $\left(\mathrm{COO}^{-}\right)$. The IR spectra of both eAAO and cAAO membranes indicate that the electrolyte species, such as phosphonate and citric ions, are being incorporated into the AAO framework under the high electric field. Moreover, the decrease of the reflectivity (increase in the magnitude of the absorbance) of the cAAO samples anodized under increasing anodizing potential suggests that with the electric field strength more ions are being attracted by the anode and embedded into the cAAO framework. The decrease of the reflectivity can be also caused by the increasing thickness of the cAAO-1, cAAO-2, and cAAO-3 membranes. The bands in the $400-1000 \mathrm{~cm}^{-1}$ range may be attributed to the bending and stretching vibrations of Al-O$\mathrm{Al}$ of the alumina $[52,53]$. The dips observed in the region between 519 and $595 \mathrm{~cm}^{-1}$ correspond most probably to the condensed octahedral stretching of the chemical bond $\mathrm{Al}-\mathrm{O}_{6}[47,54,55]$, whereas well-defined dips between 927 and $938 \mathrm{~cm}^{-1}$ can be assigned to the longitudinal optical phonon (LO) stretching $\left(\lambda_{\mathrm{LO}}\right)$ of the $\mathrm{Al}-\mathrm{O}$ chemical bond $[56,57]$. The dip positions corresponding to the $\mathrm{Al}-\mathrm{O}_{6}$ and $\lambda_{\mathrm{LO}}$ vibrations are different for cAAO-1 $\left(546,927 \mathrm{~cm}^{-1}\right)$, cAAO-2 $\left(519,931 \mathrm{~cm}^{-1}\right)$, and cAAO-3 $\left(595,938 \mathrm{~cm}^{-1}\right)$ membranes, most probably owing to a somewhat different position the citric ions are attached to the Al-O structure and perhaps to a different amount of citric ions incorporated in the cAAO walls. Both effects will certainly affect the $\mathrm{Al}-\mathrm{O}_{6}$ and the $\lambda_{\mathrm{LO}}$ vibration frequency. The decrease in reflective intensity of the dips assigned to $\mathrm{Al}-\mathrm{O}_{6}$ and $\lambda_{\mathrm{LO}}$ bands with anodizing voltage corresponds with the reflectivity drop of the dips characteristic for COO- vibrations (the 1472 and $1568 \mathrm{~cm}^{-1}$ bands). Therefore, as before, the reflectivity decrease is tentatively attributed to the higher amount of citric ions being embedded into the AAO walls 
and the greater cAAO thickness (more citric ions that can absorb IR light). It was shown previously that the pores play a crucial role in the redshift of the longitudinal optical phonon (LO) mode [58]. Therefore, the band positions might be slightly different than those related to the nonporous alumina. Finally, the strong decrease of reflectivity above $4000 \mathrm{~cm}^{-1}$ (below $2.5 \mu \mathrm{m}$ ) is most probably due to the antireflective properties of the graded pore structure in the NIR spectral region. It can be seen that the eAAO-3 membrane with greatest $D_{c}$ and thickness values has the largest ability to trap light in this spectral range.

\section{Conclusions}

In this work, conical-pore AAO membranes with $D_{c}$ between around 530 and $620 \mathrm{~nm}$ and the thickness ranging between 2.4 and $7.8 \mu \mathrm{m}$, were fabricated. In the fabrication process a guided anodization was applied. Aluminum surface was first pre-patterned by the anodization in etidronic acid solution. Then, the $\mathrm{Al}$ concave arrays were used as nucleation sites to grow highly regular AAO in the second anodization. The second anodization was conducted in highly concentrated citric acid solution $(20 \mathrm{wt} \%)$ and at relatively high temperature $\left(33-35^{\circ} \mathrm{C}\right)$. The pore shape was engineered during a multistep process alternating between anodization in the citric acid electrolyte and chemical pore broadening in phosphoric acid solution. The morphological analyses has revealed that the geometrical parameters of the $\mathrm{Al}$ concaves were successfully transferred to the cAAO membranes. FTIR spectra analysis confirmed that the electrolyte species, such as phosphonate and citric ions, are being incorporated into the AAO framework during the anodization. The graded-index AAO membranes can be used as a template for a production of antireflective coatings in a broad spectral range.

Open Access This article is distributed under the terms of the Creative Commons Attribution 4.0 International License (http:// creativecommons.org/licenses/by/4.0/), which permits unrestricted use, distribution, and reproduction in any medium, provided you give appropriate credit to the original author(s) and the source, provide a link to the Creative Commons license, and indicate if changes were made.

\section{References}

1. A. M. Md Jani, D. Losic, N.H. Voelcker, Progr. Mater. Sci. 58, 636 (2013).

2. G. E. J. Poinern, N. Ali, D. Fawcett, Materials 4, 487 (2011).

3. G.D. Sulka in Nanostructured Materials in Electrochemistry, ed. by A. Eftekhari (Wiley, Weinheim, 2008) p. 1

4. T. Kikuchi, D. Nakajima, O. Nishinaga, S. Natsui, O.R. Suzuki, Curr. Nanosci. 11, 560 (2015).
5. T. Kikuchi, O. Nishinaga, S. Natsui, O.R. Suzuki, Electrochim. Acta 156, 235 (2015)

6. A. Takenaga, T. Kikuchi, S. Natsui, O.R. Suzuki, Electrochim. Acta 211, 515 (2016)

7. A. Mozalev, I. Mozaleva, M. Sakairi, H. Takahashi, Electrochim. Acta 50, 5065 (2005)

8. J. Bellemare, F. Sirois, D. Ménard, J. Electrochem. Soc. 161, E75 (2014)

9. J. Bellemare, L.-P. Carignan, F. Sirois, D. Ménard, J. Electrochem. Soc. 162, E47 (2015)

10. Y. Katsuta, A. Yasumori, K. Wada, K. Kurashima, S. Suehara, S. Inoue, J. Non-Cryst. Sol. 354, 451 (2008)

11. Q. Wang, Y. Long, B. Sun, J. Porous Mater. 20, 785 (2013)

12. X. Chen, D. Yu, L. Cao, X. Zhu, Y. Song, H. Huang, L. Lu, X. Chen, Mater. Res. Bull. 57, 116 (2014)

13. K. Surawathanawises, X. Cheng, Electrochim. Acta 117, 498 (2014)

14. J.M. Montero-Moreno, M. Waleczek, S. Martens, R. Zierold, D. Görlitz, V.V. Martínez, V.M. Prida, K. Nielsch, Adv. Funct. Mater. 24, 1857 (2014)

15. H. Masuda, H. Yamada, M. Satoh, H. Asoh, M. Nakao, T. Tamamura, Appl. Phys. Lett. 71, 2770 (1997)

16. W. Lee W, K. Nielsch, U. Gösele, Nanotechnology 18, 475713 (2007)

17. J. Liu, S. Liu, H. Zhou, C. Xie, Z. Xuang, C. Fu, Y. Kuang, Thin Solid Films 552, 75 (2014)

18. X.Y. Han, W.Z. Shen, J. Electroanal. Chem. 655, 56 (2011)

19. W. Lee, K. Schwirn, M. Steinhart, E. Pippel, R. Scholz, U. Gösele, Nat. Nanotechnol. 3, 234 (2008)

20. W. Lee, J.C. Kim, Nanotechnology 21, 485304 (2010)

21. J. Li, C. Li, X. Gao, Appl. Surf. Sci. 257, 10390 (2011)

22. C. Li, J. Li, C. Chen, J. Zhu, X. Gao, Chem. Commun. 48, $5100(2012)$

23. J. Li, C. Li, C. Chen, Q. Hao, Z. Wang, J. Zhu, X. Gao, ACS Appl. Mater. Interfaces 4, 5678 (2012)

24. B. Sun, J. Li, X. Jin, C. Zhou, Q. Hao, X. Gao, Electrochim. Acta 112, 327 (2013)

25. K. H. Lee, X.Y. Lim, W. Kah, F. Romanato, C.C. Wong, J. Nanosci. Nanotech. 11, 1147 (2011)

26. J. Ferré-Borrul, J. Pallarés, G. Macías, L.F. Marsal, Materials 7, 5225 (2014)

27. G. Hubbard, M.E. Nasir, P. Shields, C.R. Bowen, A. Satka, K.P. Parsons, N.H. Holmes, D.W.E. Allsopp, Nanotechnology 23, 155302 (2012)

28. H.K. Raut, S.S. Dinachali, Y.C. Loke, R. Ganesan, K.K. Ansah-Antwi, A. Góra, E.H. Khoo, V.A. Ganesh, M.S.M. Saifullah, S. Ramakrishna, ACS Nano 9, 1305 (2015)

29. A. Rahman, A. Ashraf, H. Xin, X. Tong, P. Sutter, M. D. Eisaman, C. T. Black, Nat. Comm. 6, 5963 (2015)

30. A. Asadollahbaik, S.A. Boden, M.D.B. Charlton, D.N.R. Payne, S. Cox, D.M. Bagnall, Opt. Express 22, A402 (2014)

31. K. Choi, S.H. Park, Y.M. Song, Y.T. Lee, C.K. Hwangbo, H. Yang, S.H. Lee, Adv. Mater. 22, 3713 (2010)

32. K. Choi, S.H. Park, Y.M. Song, C. Choc, S.H. Lee, J. Mater. Chem. 22, 17037 (2012)

33. F.L. Gonzalez, M.J. Gordon, Opt. Express 22, 12808 (2014)

34. J. Li, J. Zhu, X. Gao, Small 10, 2578 (2014)

35. I. Horcas, R. Fernandez, J.M. Gomez-Rodriguez, J. Colchero, J. Gomez-Herrero, A.M. Baro, Rev. Sci. Instrum. 78, 013705 (2007)

36. WSxM, http://www.nanotec.es

37. W. J. Stępniowski, D. Zasada, Z. Bojar, Surf. Coat. Technol. 206, 1416 (2011)

38. W. J. Stępniowski, A. Nowak-Stępniowska, Z. Bojar, Mater. Charact. 78, 79 (2013) 
39. S. Ono, M. Saito, H. Asoh, Electrochem. Solid-State Lett. 7, B21 (2004)

40. S. Ono, M. Saito, M. Ishiguro, H. Asoh, J. Electrochem. Soc. 151, B473 (2004)

41. S.Z. Chu, K. Wada, S. Inoue, M. Isogai, Y. Katsuta, A. Yasumori, J. Electrochem. Soc. 153, B384 (2006)

42. K. Ebihara, H. Takahashi, M. Nagayama, J. Met. Finish. Soc. Jpn. 34, 548 (1983)

43. J.P. O'Sullivan, G.C. Wood, Proc. R. Soc. Lond. A 317, 511 (1970)

44. W. J. Stępniowski, Z. Bojar, Surf. Coat. Technol. 206, 265 (2011).

45. S.H. Chen, D.-S. Chan, C.-K. Chen, T.-H. Chang, Y.-H. Lai, C.-C. Lee, Jpn. J. Appl. Phys 49, 015201 (2010)

46. Y.J.O. Asencios, M.R. Sun-Kou, Appl. Surf. Sci. 258, 10002 (2012)

47. I.V. Gasenkova, E.V. Ostapenko, N.I. Mazurenko, J. Surf. Invest. 8, 636 (2014)
48. M.C. Zenobi, C.V. Luengo, M.J. Avena, E.H. Rueda, Spectrochimica Acta Part A 70, 270 (2008)

49. W. Gong, Int. J. Miner. Process. 63, 147 (2001)

50. B. R. Lakshmanan, J. Ind. Inst. Sci. 39, 27 (1957).

51. J. C. Mohan, G. Praveen, K. P. Chennazhi, R. Jayakumarand, S.V. Nair, J. Exp. Nanosci. 8, 32 (2013)

52. Y. Yang, Q. Gao, Phys. Lett. A 333, 328 (2004)

53. I.F. Myronyuk, V.I. Mandzyuk, V.M. Sachko, V.M. Gun'ko, Nanoscale Res. Lett. 11, 153 (2016)

54. P. Tarte, Spectrochim. Acta 23A, 2127 (1967)

55. F. Fondeur, J.L. Koenig, J. Adhes. 40, 189 (1993)

56. J.M. Reyes, B.M. Perez Ramos, C.Z. Islas, W.C. Arriaga, P.R. Quintero, A.T. Jacome, J. Electrochem. Soc 160, B201 (2013)

57. L.T. Jurado, R.M.A. Hernández, E. Rocha-Rangel, J. Powder Technol. 268070, 7 (2013)

58. E. Wackelgard, J. Phys. 8, 4289 (1996) 